\title{
Pathogenesis of Periodontitis: A Major Arginine-specific Cysteine Proteinase from Porphyromonas gingivalis Induces Vascular Permeability Enhancement through Activation of the Kallikrein/Kinin Pathway
}

Takahisa Imamura, * Robert N. Pike, Jan Potempa, ${ }^{\star}$ and James Travis

The Department of Biochemistry, University of Georgia, Athens, Georgia 30602; * Division of Molecular Pathology, Department of Neuroscience and Immunology, Kumamoto University Graduate School of Medical Sciences, Kumamoto 860, Japan; and ${ }^{\ddagger}$ Department of Microbiology and Immunology, Institute of Molecular Biology, Jagiellonian University, 31-120 Krakow, Poland

\begin{abstract}
To elucidate the mechanism of production of an inflammatory exudate, gingival crevicular fluid (GCF), from periodontal pockets in periodontitis, we examined the vascular permeability enhancement (VPE) activity induced by an arginine-specific cysteine proteinase, Arg-gingipain-1 (RGP1), produced by a major periopathogenic bacterium, Porphyromonas gingivalis. Intradermal injections into guinea pigs of RGP-1 $\left(>10^{-8} \mathrm{M}\right)$, or human plasma incubated with RGP-1 $\left(>10^{-9} \mathrm{M}\right)$, induced VPE in a dose- and activitydependent manner but with different time courses for the two routes of production. VPE activity induced by RGP-1 was augmented by kininase inhibitors, inhibited by a kallikrein inhibitor and unafiected by an antihistamine drug. The VPE activity in human plasma incubated with RGP-1 also correlated closely with generation of bradykinin (BK). RGP-1 induced 30-40\% less VPE activity in Hageman factor-deficient plasma and no VPE in plasma deficient in either prekallikrein (PK) or high molecular weight kininogen (HMWK). After incubation with RGP-1, plasma deficient in PK or HMWK, reconstituted with each missing protein, caused VPE, as did a mixture of purified PK and HMWK, but RGP-1 induced no VPE from HMWK. The VPE of extracts of clinically isolated $P$. gingivalis were reduced to about $10 \%$ by anti-RGP-1-IgG, leupeptin, or tosylL-lysine chloromethyl ketone, which paralleled effects observed with RGP-1. These results indicate that RGP-1 is the major VPE factor of $P$. gingivalis, inducing this activity through $P K$ activation and subsequent $B K$ release, resulting in GCF production at sites of periodontitis caused by infection with this organism. (J. Clin. Invest. 1994. 94:361-367.) Key words: bradykinin - prekallikrein - high molecular weight kininogen $\cdot$ bacteria $\cdot$ gingival crevicular fluid
\end{abstract}

\section{Introduction}

The declining incidence of dental caries in the general population has resulted in periodontal disease assuming major impor-

Address correspondence to J. Travis, Department of Biochemistry, University of Georgia, Athens, GA 30602.

Received for publication 6 December 1993 and in revised form 4 March 1994.

J. Clin. Invest.

(c) The American Society for Clinical Investigation, Inc.

0021-9738/94/07/0361/07 \$2.00

Volume 94, July 1994, 361-367 tance as a cause of tooth loss $(1,2)$. Adult periodontitis is strongly associated with infection by Porphyromonas gingivalis (formerly Bacteroides gingivalis) (3-7), which is further demonstrated by the finding that implantation of this bacterium initiates the progression of periodontitis (8). Proteolytic enzymes, which are produced in large quantity by this bacteria, are considered as important pathogenic agents (9-11). From a biochemical viewpoint, enzymes have been identified which hydrolyze complement factor C5 $(12,13)$, releasing a C5a-like neutrophil chemotactic fragment $(14,15)$, which is likely to be involved in leukocyte infiltration of the gingiva. In addition, collagenases released $(16,17)$ may contribute to the loss of periodontal attachment associated with progressive periodontal disease.

The increased production and flow of gingival crevicular fluid (GCF) ${ }^{1}$ is an important change in gingival tissues during periodontal infection, correlating with clinical indices of gingival inflammation (18-23). Indeed, salivary protein and albumin concentrations of individuals with periodontitis, which are an indication of plasma leakage due to vascular permeability enhancement (VPE), are significantly increased compared to healthy subjects (24). These findings suggest that production of GCF is dependent on VPE induced at periodontitis sites, but little is known about the source or generation of VPE factor( $(s)$ and, more specifically, whether proteinase(s) of $P$. gingivalis are involved in their generation.

Histamine, bradykinin, thrombin, and fibrinogen derivatives are potent VPE factors, and the generation of these factors is associated with the presence of trypsin-like proteinases. Histamine is released from mast cells by $\mathrm{C} 3 \mathrm{a}$, which is produced by the cleavage of complement factor C3 (25). Bradykinin (BK) is generated from high molecular weight kininogen (HMWK) either directly, or indirectly, through activation of Hageman factor (HF) and/or plasma prekallikrein (PK) $(26,27)$, a process which is also used by some microbial proteinases to generate BK (28-30). Thrombin (31) and fibrinogen derivatives (32) are products of the proteolytic cascades of blood coagulation or fibrinogenolysis, respectively.

Proteinases from $P$. gingivalis have been found to hydrolyze C3 $(12,15)$, plasma PK, prothrombin complex, plasminogen, and fibrinogen (33), suggesting a number of mechanisms for the generation of VPE factor(s) by proteinase $(s)$ from this

1. Abbreviations used in this paper: BK, bradykinin; FPR-CK, H-DPhe-Pro-Arg-chloromethylketone; GCF, gingival crevicular fluid; HF, Hageman factor; HMWK, high molecular weight kininogen; PK, plasma prekallikrein; RGP-1, Arginine-specific gingipain-1; SBTI, soybean trypsin inhibitor; TLCK, tosyl-L-lysine chloromethylketone; VPE, vascular permeability enhancement; Z-FK-CK, benzyloxycarbonyl-PheLys- $\mathrm{Ch}_{2} \mathrm{OCO}-\left(2,4,6-\mathrm{Me}_{3}\right) \mathrm{Ph} \cdot \mathrm{HCl}$. 
bacterium. Recently, we purified and characterized argininespecific gingipain-1 (RGP-1), $50 \mathrm{kD}$ (34) and lysine-specific, $105 \mathrm{kD}$ (KGP-1) (35) cysteine proteinases from $P$. gingivalis. The data presented below clearly indicate the potency of RGP1 for inducing VPE, in vivo, and the mechanism by which this occurs.

\section{Materials}

Materials. Bradykinin, angiotensin I converting enzyme inhibitor SQ 20,881 (pGlu-Trp-Pro-Arg-Pro-Gln-Ile-Pro-Pro), 1,10-phenanthroline, soybean trypsin inhibitor (SBTI), tosyl-L-lysine chloromethyl ketone (TLCK), histamine, diphenhydramine, Evans blue dye, and plasmas deficient in HF, PK, or HMWK were purchased from Sigma Chemical Co. (St. Louis, MO). Leupeptin was a product of Boehringer Mannheim Corp. (Indianapolis, IN). Benzyloxycarbonyl-Phe-Lys- $\mathrm{CH}_{2} \mathrm{OCO}-$ $\left(2,4,6-\mathrm{Me}_{3}\right) \mathrm{Ph} \cdot \mathrm{HCl}(\mathrm{Z}-\mathrm{FK}-\mathrm{CK})$ was kindly donated by Dr. A. Krantz (Syntex, Toronto, ON, Canada). H-D-Phe-Pro-Arg-chloromethylketone (FPR-CK) was from BACHEM Bioscience, Inc. (Philadelphia, PA). Purified PK and HMWK were purchased from Enzyme Research Laboratories, Inc. (South Bend, IN). These proteins were homogenous as judged by $10 \%$ SDS-PAGE gels and showed no reduction after boiling in the presence of 5\% DTT. Markit-A bradykinin kit was purchased from Dainippon Pharmaceuticals (Osaka, Japan). Normal human plasma was obtained from healthy volunteers by adding 9 vol of freshly drawn blood to $1 \mathrm{vol}$ of $3.8 \%$ ( $\mathrm{wt} / \mathrm{vol}$ ) sodium citrate, followed by centrifugation. Albino-Hartley strain male guinea pigs (300-400 g body weight) were obtained from Charles River Lab (Wilmington, MA).

Proteinase purification. RGP-1 was purified according to the method of Chen et al. (34) and migrated as a single band on SDS-PAGE gels as shown previously $(34,35)$. The amount of active enzyme present in the purified proteinase was determined by active site titration using FPR-CK (Potempa et al., manuscript in preparation). Briefly, activated RGP-1 was preincubated with increasing amounts of FPR-CK, followed by measurement of residual enzyme activity with BAPNA. The concentration of RGP-1 was calculated from the amount of inhibitor needed for complete RGP-1 inactivation.

$V P E$ assay. Guinea pigs were anesthetized with an intramuscular injection of Ketamine ( $80 \mathrm{mg} / \mathrm{kg}$ body weight $) .30 \mathrm{mg} / \mathrm{kg}$ body weight of Evans blue dye ( $2.5 \%$ solution in $0.6 \%$ saline) was then administered intravenously, followed by an intradermal injection of $0.1 \mathrm{ml}$ of RGP1 solution (previously dialyzed against $10 \mathrm{mM}$ Tris- $\mathrm{HCl}, 150 \mathrm{mM} \mathrm{NaCl}$ [TBS] and diluted with $1 \mathrm{mM}$ DTT, $100 \mu \mathrm{g} / \mathrm{ml} \mathrm{BSA}$ in TBS) into the clipped flank of the guinea pig. VPE activity of the sample was determined by quantitatively measuring the Evans blue dye extravasated (usually $15 \mathrm{~min}$ after injection), according to the method of Udaka et al. (36). Activity was expressed in micrograms of dye released. Dye leakage at a site injected with TBS was used as a control.

Measurement of the activity generated when human plasma was incubated with RGP-1 was obtained by first incubating $50 \mu \mathrm{l}$ of plasma, supplemented with 1,10-phenanthroline $(2 \mathrm{mM})$, with an equal volume of RGP-1 (treated as above), at $25^{\circ} \mathrm{C}$, for varying time periods. The reaction was stopped by adding $400 \mu \mathrm{l}$ of TBS, supplemented with 1,10 phenanthroline $(1 \mathrm{mM})$, SBTI $\left(2 \times 10^{-5} \mathrm{M}\right)$, and FPR-CK $(20 \mu \mathrm{M})$ (stop solution), and the VPE activity of the sample was assayed, as described above.

$B K$ assay. Bradykinin quantification using a Markit-A bradykinin kit was carried out according to the manufacturers instructions.

Preparation of bacterial cell extract. $P$. gingivalis OMGS 100 was grown for 3 to $4 \mathrm{~d}$ in $95 \% \mathrm{~N}_{2}$ and $5 \% \mathrm{CO}_{2}$ saturated anaerobic chambers on Brucella agar (BBL Microbiology Systems, Cockeysville, MD), supplemented with $0.5 \mathrm{ml}$ of horse blood and $0.05 \mathrm{ml}$ of hemolyzed human erythrocytes per liter, and $5 \mathrm{mg}$ of menadione per ml. Bacterial cells collected from the agar surface were washed twice in PBS and lyophilized. Crude extracts were obtained by suspending $25 \mathrm{mg}$ of the lyophilized cells in $1 \mathrm{ml}$ of $10 \mathrm{mM}$ Tris- $\mathrm{HCl}, 150 \mathrm{mM} \mathrm{NaCl}, 1 \mathrm{mM}$ DTT, $\mathrm{pH} 7.4$, followed by lysis of the cells by ultrasonication $(6 \mathrm{kHz}$

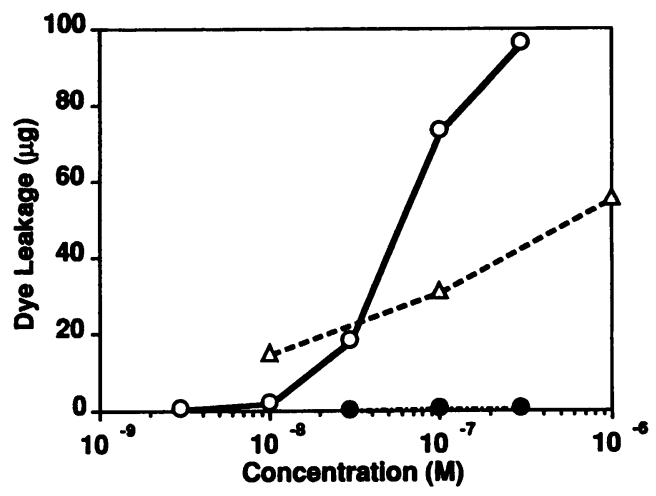

Figure 1. Dose- and proteinase-dependence of vascular permeability enhancement activity of RGP-1. Sample $(100 \mu \mathrm{l})$ was injected intradermally into a guinea pig after giving $30 \mathrm{mg} / \mathrm{kg}$ body weight of Evans blue intravenously. After $15 \mathrm{~min}$, the guinea pig was euthanized by exsanguination and the skin at the injection site taken. The latter was incubated in formamide at $60^{\circ} \mathrm{C}$ for $48 \mathrm{~h}$ and the extracted dye quantified spectrophotometrically at $620 \mathrm{~nm}$. (O) RGP-1; (•) RGP-1 inactivated with TLCK; $(\Delta)$ BK.

for $30 \mathrm{~min}$ on ice, including $1 \mathrm{~s}$ pauses every $2 \mathrm{~s}$ of sonication). Unbroken cells and large cell debris were removed by centrifugation at 13,000 $g$ for $15 \mathrm{~min}$, and the clear supernatant which contained bacterial membranes, in addition to soluble components, was retained.

Enzyme activity assay. The amidolytic, trypsin-like activity of crude $P$. gingivalis cell extract and purified RGP-1 was determined using BzL-Arg-pNA. Samples were preincubated in $0.1 \mathrm{M}$ Tris- $\mathrm{HCl}, 200 \mathrm{mM}$

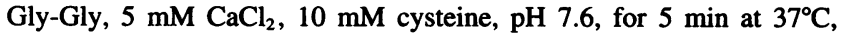
and then assayed for amidase activity, using $1 \mathrm{mM}$ substrate. The formation of $p$-nitroaniline was monitored spectrophotometrically at $405 \mathrm{~nm}$.

Production of rabbit anti-gingipain IgG. Antibodies against gingipain were raised by subcutaneous inoculation of rabbits with $50 \mu \mathrm{g}$ of enzyme emulsified in Freund's complete adjuvant. Booster injections with the same dose of enzyme, emulsified in Freund's incomplete adjuvant, were given after 2 wk and then monthly. Rabbits were bled after 10 wk by cardiac puncture and IgG prepared from the sera using PEG precipitation, according to the method of Polson et al. (37).

Inhibition of RGP-1 or P. gingivalis extracts by anti-RGP-1-IgG or proteinase inhibitors. RGP-1 $(2.5 \mu \mathrm{g})$ was preincubated with $200 \mu \mathrm{g}$ of either specific rabbit anti-RGP-1 IgG or non-specific rabbit IgG, 200 $\mu \mathrm{M}$ leupeptin, $4 \mathrm{mM}$ TLCK, or $20 \mu \mathrm{M}$ Z-FK-CK in $260 \mu \mathrm{l}$ of $10 \mathrm{mM}$ Tris- $\mathrm{HCl}, 150 \mathrm{mM} \mathrm{NaCl}, 1 \mathrm{mM}$ cysteine, $\mathrm{pH} 7.4$, containing $0.1 \mathrm{mg}$ $\mathrm{BSA} / \mathrm{ml}$ (final enzyme concentration: $5 \times 10^{-8} \mathrm{M}$ ) for $30 \mathrm{~min}$ at room temperature, before being used in in vitro experiments. $P$. gingivalis extracts, adjusted to an equivalent RGP-1 concentration in terms of relative BAPNA hydrolyzing activity, were treated in the same way.

\section{Results}

$V P E$ by RGP-1 injected into guinea pig skin. Direct intradermal injection of RGP-1 induced VPE at concentrations of $10^{-8} \mathrm{M}$ and above in a dose-dependent manner, but RGP-1 inactivated with TLCK had no effect (Fig. 1). As expected, BK also induced VPE in a dose-dependent manner. The activity induced by RGP-1 showed a steeper stimulation than that found with BK, which showed an almost linear generation of VPE with a logarithmic increase of concentration (Fig. 1). Using $10^{-8} \mathrm{M}$ RGP-1, VPE increased until 15 min after injection (19-fold) and then diminished slowly, while BK-induced activity decreased rapidly after injection, most of the activity being eliminated in $15 \mathrm{~min}$ (Fig. 2). These results indicate that the delayed genera- 


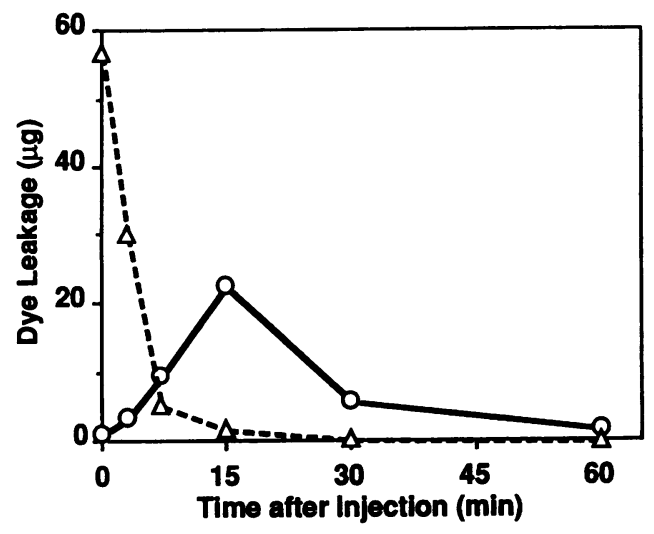

Figure 2. Time-course of vascular permeability enhancement activity in guinea pig skin. $100 \mu \mathrm{l}$ of RGP-1 $\left(10^{-8} \mathrm{M}\right)$ or BK $\left(10^{-6} \mathrm{M}\right)$ was intradermally injected into a guinea pig $3,7,15,30$, and $60 \mathrm{~min}$ before intravenous injection of Evans blue. Dye leaked at the injected sites was quantified as described in Fig. 1. The dye leakage at injection sites immediately after intravenous injection of Evans blue was shown as 0 min. (O) $10^{-8}$ M RGP-1; $(\Delta) 10^{-6} \mathrm{M} \mathrm{BK}$.

tion of VPE activity by RGP-1, in relation to direct injections of $\mathrm{BK}$, is associated with its enzymatic activity and suggests that a cascade reaction may be involved in its production.

Characterization of VPE. To identify the mechanism by which RGP-1 induced VPE, the effect of a variety inhibitors was tested. VPE production was not inhibited by simultaneous injection of diphenhydramine, an anti-histamine drug, whereas in controls the VPE generated by histamine was completely blocked (Fig. 3). The simultaneous injection of SQ 20,881, an inhibitor of angiotensin I converting enzyme (38), which is a BK inactivator, stimulated the VPE induced by RGP-1 (Fig. 3 ). In controls this compound also augmented the VPE induced by BK but did not affect the VPE mediated by histamine. The simultaneous injection of SBTI completely inhibited the VPE produced by RGP-1, at a concentration at which this proteinase inhibitor does not affect the proteinase activity of RGP-1 (Fig.

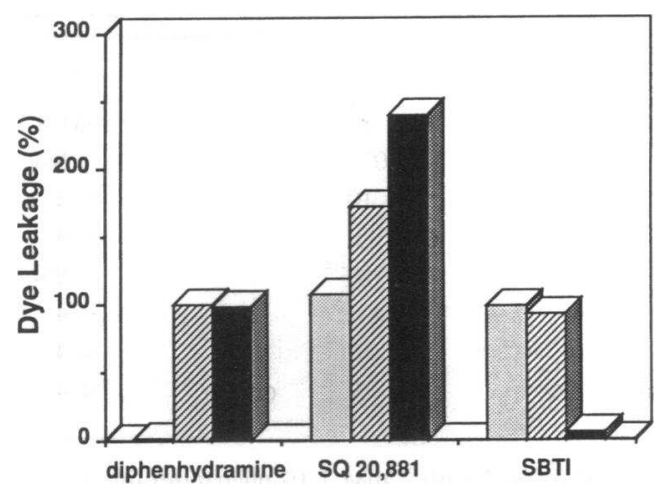

Figure 3. The effect of inhibitors on vascular permeability enhancement activity of RGP-1. 100- $\mu$ l of histamine $\left(10^{-5} \mathrm{M}\right)$, BK $\left(10^{-7} \mathrm{M}\right)$ or RGP-1 $\left(3 \times 10^{-8} \mathrm{M}\right)$ was intradermally injected into a guinea pig simultaneously with diphenhydramine $\left(10^{-4} \mathrm{M}\right)$, SQ 20,881 $\left(10^{-5} \mathrm{M}\right)$, or SBTI $\left(10^{-5} \mathrm{M}\right)$, after intravenous injection of Evans blue into the animal. The dye in each injected site was measured as described in Fig. 1. (図) histamine; (घ) BK; (घ) RGP-1.

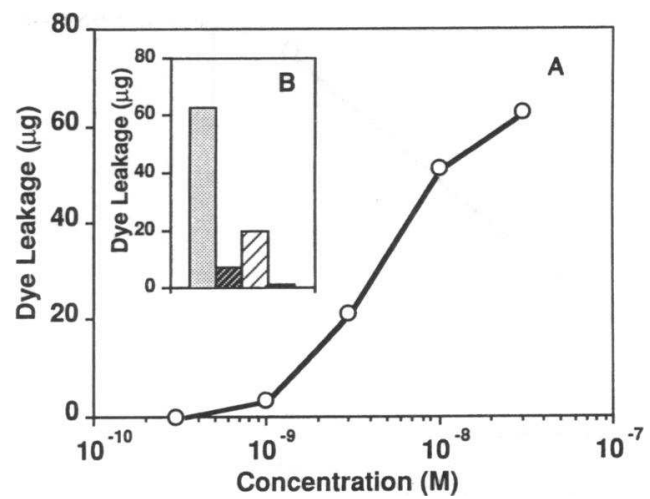

Figure 4. Generation of vascular permeability enhancement activity from normal human plasma by RGP-1 and the effect of inhibitors. $(A)$ Plasma $(50 \mu \mathrm{l})$ supplemented with 1,10-phenanthroline $(2 \mathrm{mM})$, was incubated with an equal volume of varying concentrations of RGP-1 at $25^{\circ} \mathrm{C}$ for $5 \mathrm{~min}$, followed by the addition of $400 \mu \mathrm{l}$ stop solution. This solution $(100 \mu \mathrm{l})$ was injected intradermally into a guinea pig, pretreated with Evans blue. The VPE activity $(0)$ was assayed as described in Fig. 1. (B) The same experiment as above was repeated, in the presence of inhibitors, at one RGP-1 concentration $\left(10^{-8} \mathrm{M}\right)$. (田) plasma incubated with RGP-1 as above; $(\mathbb{\Xi})$ plasma incubated with RGP-1 in the presence of SBTI (ש) plasma incubated with RGP-1 in the absence of 1,10-phenanthroline; and ( $\square$ ) plasma incubated with RGP-1 inactivated with TLCK.

3), while having no effect on the VPE produced by BK or histamine. Plasma kallikrein releases BK from HMWK and SBTI inhibits the hydrolytic (39) and VPE-inducing (26) activities of plasma kallikrein. Thus, these results indicate that the VPE generated by RGP-1 is caused by the ultimate release of $\mathrm{BK}$ and is probably mediated by the initial activation of plasma prekallikrein to kallikrein.

$V P E$ by human plasma treated with RGP-1. To investigate whether RGP-1 caused the production of VPE in man, human plasma was incubated with RGP-1, followed by injection into guinea pig skin. Human plasma-induced VPE in a dose-dependent manner after incubation with RGP-1 at concentrations as low as $10^{-9} \mathrm{M}$ (Fig. 4). The VPE of human plasma incubated with RGP-1 decreased markedly in the presence of SBTI or in the absence of 1,10-phenanthroline (Fig. 4) (an inhibitor of kininases [40]). The VPE of plasma incubated with RGP-1 $\left(10^{-9} \mathrm{M}\right)$ increased linearly with incubation time (Fig. 5), indicating that no plasma proteinase inhibitors were affecting its production. TLCK-inactivated RGP-1 did not generate VPE activity from plasma even after longer incubation periods (Fig. 5 ). These results indicate that RGP-1 acts in the same way in human plasma, inducing VPE through plasma kallikreinmediated $\mathrm{BK}$ generation.

$V P E$ by deficient plasmas treated with RGP-1. To further investigate the mechanism of VPE production in human plasma treated with RGP-1, we examined its action in plasmas deficient in HF, PK, or HMWK. The enzyme generated VPE activity in HF-deficient plasma in a dose-dependent manner, but the VPE was $30-40 \%$ less than that of normal plasma (Fig. 6). Plasma deficient in either PK or HMWK did not stimulate VPE after incubation with RGP-1 (Fig. 6). However, RGP-1 induced VPE from HMWK-deficient plasma reconstituted to normal levels by addition of HMWK (41) or PK-deficient plasma reconstitu- 


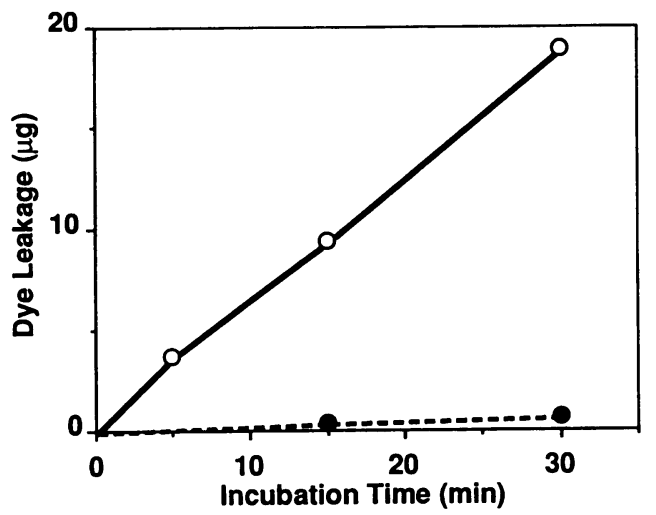

Figure 5. Time-course of generation of vascular permeability enhancement activity from normal human plasma by RGP-1. Plasma ( $50 \mu \mathrm{l})$, supplemented with $2 \mathrm{mM} \mathrm{1,10-phenanthroline} \mathrm{and} 2 \mathrm{mM}$ cysteine was incubated with $50 \mu$ lof RGP-1 $\left(2 \times 10^{-9} \mathrm{M}\right)$ for various periods, followed by the addition of $400 \mu \mathrm{l}$ of stop solution. This solution ( 100 $\mu \mathrm{l})$ was injected intradermally into a guinea pig, pretreated with Evans blue. The VPE activity was assayed as described in Fig. 1. (O) RGP$1 ;(\bullet)$ RGP-1 inactivated with TLCK.

ted with PK (41) (Fig. 7). These results demonstrate that RGP1 induces VPE by generating BK via activation of prekallikrein but not directly from HMWK.

Release of BK from plasma by RGP-1. To confirm the release of BK by RGP-1 in human plasma, BK antigen in plasma treated with RGP-1 was quantified. Release of BK antigen in normal plasma, treated with RGP-1, increased in a dose-dependent manner (Table I), as it did in HF-deficient plasma, but in this case the $\mathrm{BK}$ release was much less than that from normal plasma. The release of BK antigen from PK or HMWK-deficient plasmas was lower than the detection limit (Table I). Considering the dose-response of VPE generated by BK (Fig. 1), the concentrations of BK released from RGP-1 - treated plasma cor-

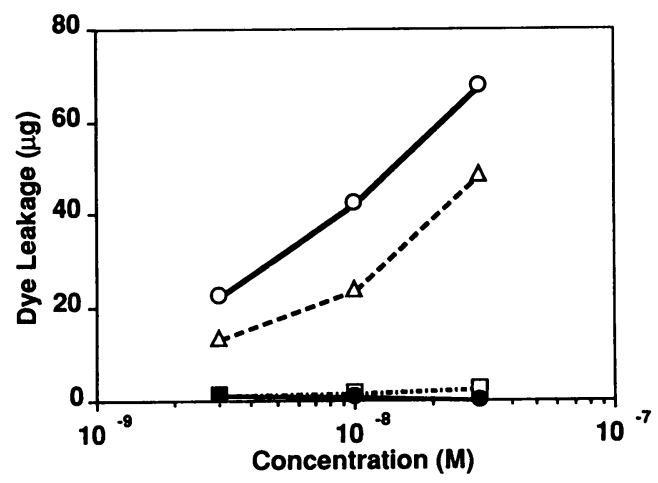

Figure 6. Comparison of plasmas deficient in HF, PK, or HMWK with normal plasma in generation of vascular permeability enhancement activity by RGP-1. Normal plasma $(50 \mu \mathrm{l})$, or plasmas deficient in HF, PK, or HMWK, supplemented with 1,10-phenanthroline ( $2 \mathrm{mM}$ ), were incubated with RGP-1 for $5 \mathrm{~min}$. The reaction was stopped by adding $400 \mu \mathrm{l}$ of stop solution and $100 \mu \mathrm{l}$ of the solution was injected intradermally into a guinea pig, pretreated, with Evans blue. The VPE activity was assayed as described in Fig. 1. The concentrations in the reaction mixtures are shown. $(O)$ normal plasma; $(\triangle)$ HF-deficient plasma; $(\square)$ PK-deficient plasma; $(\bullet)$ HMWK-deficient plasma.

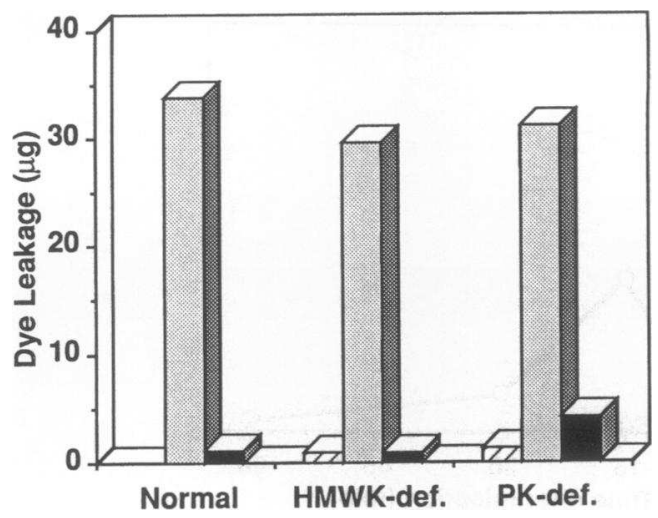

Figure 7. Generation of vascular permeability enhancement activity by incubation of RGP-1 with deficient plasmas reconstituted with each deficient factor. Five microliters of TBS, HMWK $(700 \mu \mathrm{g} / \mathrm{ml})$, or PK ( $150 \mu \mathrm{g} / \mathrm{ml})$ were added to $45 \mu \mathrm{l}$ of normal plasma, or plasmas deficient in HMWK or PK, respectively. Then, $50 \mu \mathrm{l}$ of RGP-1 $\left(6 \times 10^{-8} \mathrm{M}\right)$ or TBS was added to the plasma and incubated for $5 \mathrm{~min}$ at $25^{\circ} \mathrm{C}$. The reaction was stopped by adding $400 \mu \mathrm{l}$ of stop solution and $100 \mu \mathrm{l}$ of the solution was injected intradermally into a guinea pig, pretreated with Evans blue. The VPE activity was assayed as described in Fig. 1. (ש) Plasma incubated with RGP-1; (圆) reconstituted plasma incubated with RGP-1; ( $\square$ ) reconstituted plasma incubated with TBS used for dilution of RGP-1.

related closely to the VPE of RGP-1 -treated normal plasma or plasmas deficient in HF, PK, or HMWK (Fig. 6).

$V P E$ by a mixture of purified $P K$ and HMWK treated with $R G P-1$. To confirm the mechanism of VPE by RGP-1, we examined the generation of VPE activity from HMWK or the mixture of PK and HMWK, after treatment with enzyme. RGP-1 did not induce VPE from HMWK alone but could be demonstrated in a mixture of PK and HMWK, which was also dependent on

Table I. Release of BK from Plasma Incubated with RGP-I

\begin{tabular}{lcc}
\hline \multicolumn{1}{c}{ Plasma } & RGP-1 concentration & BK release \\
\hline & $M^{*}$ & $n g$ \\
Normal & $3 \times 10^{-8}$ & 64.8 \\
Normal & $10^{-8}$ & 8.4 \\
Normal & $3 \times 10^{-9}$ & $<4$ \\
Normal & $(-)$ & $<4$ \\
HF-deficient & $3 \times 10^{-8}$ & 9.0 \\
HF-deficient & $(-)$ & $<4$ \\
PK-deficient & $3 \times 10^{-8}$ & $<4$ \\
HMWK-deficient & $3 \times 10^{-8}$ & $<4$ \\
& & \\
\hline
\end{tabular}

$50 \mu \mathrm{l}$ of plasma supplemented with $2 \mathrm{mM} \mathrm{1,10-phenanthroline} \mathrm{was}$ incubated with $50 \mu \mathrm{l}$ of RGP-1 at $25^{\circ} \mathrm{C}$ for $5 \mathrm{~min}$, followed by $400 \mu \mathrm{l}$ of TBS, containing 1,10-phenanthroline $(1 \mathrm{mM})$, SBTI $\left(10^{-5} \mathrm{M}\right)$, and H-D-FPR-CK $(20 \mu \mathrm{M})$. After adding $100 \mu \mathrm{l}$ of $20 \%$ trichloroacetic acid, the solution was centrifuged and the BK content in the supernatant assayed. The average value in the duplicate assay is shown. (-), TBS supplemented with $1 \mathrm{mM}$ dithiothreitol and $100 \mu \mathrm{g} / \mathrm{ml}$ bovine serum albumin was added to plasma instead of RGP-1; *, the concentration in the reaction mixture; $<4$ means lower than $4 \mathrm{ng}$, the detection limit. 


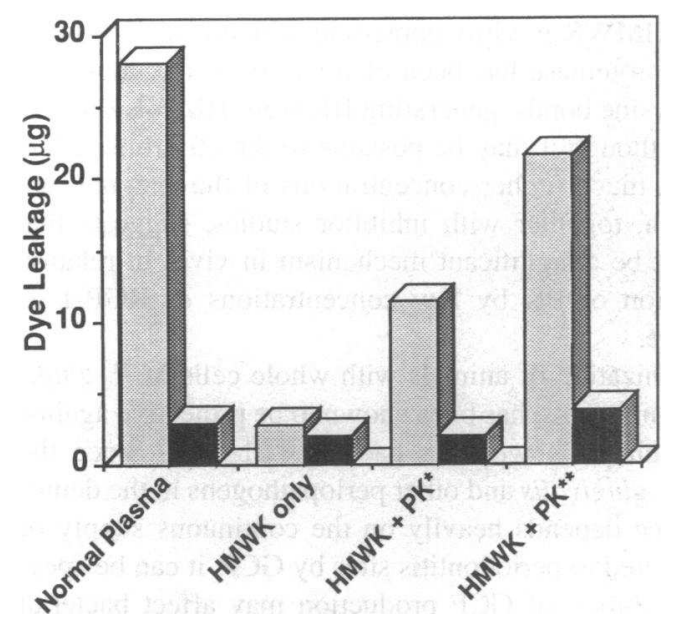

Figure 8 . Generation of vascular permeability enhancement activity by incubation of RGP-1 with the mixture of PK and HMWK. HMWK and PK were diluted with TBS containing BSA $(1 \mathrm{mg} / \mathrm{ml})$ and polybrene $(0.25 \mathrm{mg} / \mathrm{ml}) .50 \mu \mathrm{l}$ of normal plasma supplemented with 1,10-phenanthroline $(2 \mathrm{mM})$ and polybrene $(0.25 \mathrm{mg} / \mathrm{ml}), \mathrm{HMWK}$, or the mixture of HMWK and PK were incubated with $50 \mu \mathrm{l}$ of RGP-1 $\left(2 \times 10^{-8} \mathrm{M}\right)$ or TBS for $5 \mathrm{~min}$ at $25^{\circ} \mathrm{C}$. The reaction was stopped by adding $400 \mu \mathrm{l}$ of stop solution and $100 \mu \mathrm{l}$ of the solution was injected intradermally into a guinea pig, pretreated with Evans blue. The VPE activity was assayed as described in Fig. 1. The concentrations of HMWK, PK*, or $\mathrm{PK}^{* *}$ were $70 \mu \mathrm{g} / \mathrm{ml}, 0.3 \mu \mathrm{g} / \mathrm{ml}$, and $1 \mu \mathrm{g} / \mathrm{ml}$, respectively. (回) Incubated with RGP-1; ( $\square)$ incubated with TBS used for dilution of RGP-1.

the concentration of PK (Fig. 8). The amounts of BK released in RGP-1-treated normal plasma or the mixture were 6.3 and $4.7 \mathrm{ng}$, respectively, and in other samples were lower than the detection limit $(<4 \mathrm{ng}$ ). The result further demonstrated that RGP-1 caused VPE through PK activation and subsequent BK release.

Effects of RGP-1-specific IgG and proteinase inhibitors on the VPE activity of RGP-1. To determine whether RGP-1 was the major VPE factor of clinically isolated $P$. gingivalis, we examined the effects of anti-RGP-1-IgG and proteinase inhibitors on the VPE induced by RGP-1 or extracts of $P$. gingivalis strain OMGS 100. The RGP-1-specific IgG inhibited VPE mediated by either RGP-1 or the extract by 90 and $95 \%$, respectively (Fig. 9), but neither were affected by nonspecific IgG. Leupeptin, which inactivates arginine-specific $P$. gingivalis proteinases (35), completely inhibited VPE generated by RGP-1 and that of bacterial extracts by $90 \%$. Z-FK-CK, which rapidly inhibits KGP-1 (Pike, R. N., unpublished observation), did not affect VPE triggered by RGP-1, but reduced VPE by $27 \%$ in extracts. TLCK, which inhibits both arginine- and lysine-specific $P$. gingivalis proteinases (35), reduced VPE by RGP-1 completely and VPE induced by extracts to only $6 \%$. These results indicate that RGP-1 is the major VPE factor of clinically isolated $P$. gingivalis.

\section{Discussion}

In an effort to systematically characterize the effects of virulence factors from $P$. gingivalis on the human system, particularly in view of their relationship to periodontal disease, we have examined the effect of cysteine proteinases from this or-

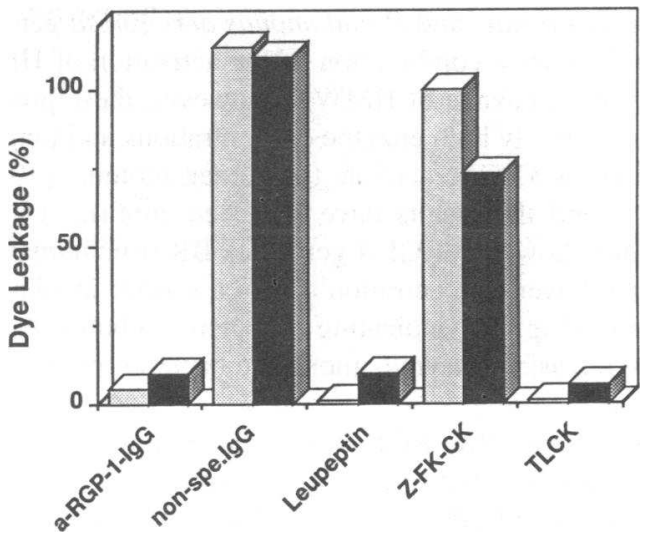

Figure 9. The effect of anti-RGP-1-IgG or proteinase inhibitors on the vascular permeability enhancement activity of both RGP-1 and Porphymonas gingivalis extracts. RGP-1 or extracts were treated with antiRGP-1-IgG (a-RGP-1-IgG), nonspecific IgG (non-spe.IgG), leupeptin, Z-FK-CK, or TLCK. Plasma ( $50 \mu \mathrm{l})$, supplemented with 1,10-phenanthroline $(2 \mathrm{mM})$, was incubated at $25^{\circ} \mathrm{C}$ for $5 \mathrm{~min}$ with either $50 \mu \mathrm{l}$ of treated RGP-1 $\left(3 \times 10^{-8} \mathrm{M}\right)$ or extracts with equivalent Bz-L-ArgpNA-cleaving activity. The VPE activity was expressed as the percentage of VPE by plasma incubated with nontreated RGP-1 or extract. (G) RGP-1; ( $\mathbf{m})$ the extract of $P$. gingivalis.

ganism on VPE (and thus GCF production). All of the data obtained clearly indicate that the arginine-specific proteinase, RGP-1, has significant VPE inducing activity, with its mechanism of production being carefully characterized.

Although the biological concentration of RGP-1 in GCF or dento-gingival pockets is not yet known, RGP-1 produced BK at low concentrations in human plasma (Table I) and induced VPE at $10^{-9} \mathrm{M}$ (Fig. 4), indicating that the enzyme would be functional in this system even at trace amounts. The data obtained by using deficient plasmas and purified PK and HMWK, clearly indicate that the major target for RGP-1 in the activation of the cascade to release bradykinin is prekallikrein. While the mechanism of activation of PK by RGP-1 is not known, the cleavage site of prekallikrein by activated HF $(\beta-\mathrm{HF})$ is at the $\operatorname{Arg}_{371}-\mathrm{Ile}_{372}$ bond (42). Since RGP-1 is strictly arginine specific (34), it probably cleaves the same site as that by $\beta$-HF. This specificity for PK may not be complete, however, since 30$40 \%$ less VPE was induced in HF-deficient plasma (Fig. 6), implying that RGP-1 may also activate HF. Kallikrein also activates $\mathrm{HF}$ to form $\beta$ - $\mathrm{HFa}$ which converts prekallikrein to kallikrein (43-48). Accordingly, kallikrein generation by RGP-1 in normal plasma could be augmented by this mechanism, while its production by RGP-1 in HF-deficient plasma would lack this additional pathway, thus explaining why VPE is reduced relative to normal plasma. In a similar manner, Pseudomonas aeruginosa elastase has been found to specifically activate human PK (49), with the generation of kallikrein from HF-deficient plasma also being much less than from normal plasma (50). Moreover, the VPE of plasma incubated with a low concentration of RGP-1 $\left(10^{-9} \mathrm{M}\right)$ increased linearly in an incubation time-dependent manner (Fig. 5), which suggests that there are no proteinase inhibitors in human plasma controlling RGP-1, as noted previously (34).

It is known that some bacterial and mite proteinases can generate BK through activation of HF and/or PK (28-30, 4953). Proteinases from Serratia marcescens, house dust mite 
Dermatophagoides farinae, and Pseudomonas aeruginosa generate BK through either a combination of the activation of $\mathrm{HF}$ and/or PK or direct cleavage of HMWK. However, these proteinases require relatively high enzyme concentrations and long incubation periods at $37^{\circ} \mathrm{C}$ to activate the human proteins ( 30 , $49,50,52,53)$, and the results have not been confirmed in vivo. In our studies, however, RGP-1 generated BK from human plasma at a much lower concentration and in a shorter incubation time at $25^{\circ} \mathrm{C}$ (Fig. 4), indicating that it is probably the most potent BK releasing enzyme among the bacterial proteinases studied to date.

In order to generate BK, RGP-1 must be in contact with PK and HMWK. Most of the trypsin-like activity of $P$. gingivalis $(54,55)$, including RGP-1, is localized in the extracellular membrane vesicles and cell membranes of invasive strains of the bacteria (Potempa, J., unpublished observation). Hence, RGP-1 should be in contact with PK and HMWK present in periodontal interstitial fluid or plasma leaked into periodontitis sites, thereby producing kallikrein and, ultimately, the liberation of BK from HMWK. This would result in a continual cycle of plasma leakage, since VPE induced by RGP-1 would result in the further recruitment of PK and HMWK around RGP-1 due to continued plasma leakage after VPE induction. This is the most likely explanation for the clinical observation that exudation of GCF is continuous, with an estimated $1 \mathrm{ml}$ of GCF passing from the gingiva into the mouth each day (57).

Most of the VPE activity of $P$. gingivalis extracts was abolished by RGP-1-specific IgG, which also inhibited the VPE induced by RGP-1 (Fig. 7). Therefore, RGP-1 is probably the major VPE factor of $P$. gingivalis. This is supported by data indicating that extracts in vivo were almost completely devoid of VPE inducing activity in leupeptin or TLCK-treated samples, both of which inhibit the proteinase activity of RGP-1, while Z-FK-CK (Fig. 7), which only partially reduces the enzymatic activity of RGP-1, also lowered VPE production. The cleavage sites to release BK from HMWK are at $\mathrm{Lys}_{326}-\mathrm{Arg}_{364}$, and $\operatorname{Arg}_{371}-\operatorname{Ser}_{372}$ (57). Since $P$. gingivalis contains both arginine and lysine-specific enzymes it is possible that these could be direct release of BK from HMWK by the concerted action of these two enzymes. We have recently isolated a lysine-specific proteinase (KGP-1) from $P$. gingivalis (35), but it alone did not induce VPE in vivo unless high concentrations were used (Imamura et al., unpublished observation). The addition of small amounts of RGP-1 to the KGP-1 preparation did allow the induction of VPE in plasma, however, including PK-deficient plasma, indicating a direct release of BK from HMWK. Since the lys-specific proteinase (KGP) from $P$. gingivalis is totally inhibited by Z-FK-CK (Pike, R. N., unpublished observation), the finding that the VPE induced by extracts, in vivo, was only partially inhibited by this compound (Fig. 7), indicates that $\mathrm{KGP}$ is not a major VPE factor of $P$. gingivalis.

Scott et al. purified a lysine-specific cysteine proteinase from $P$. gingivalis, which was claimed to directly cleave human HMWK, releasing BK antigen, as judged by an in vitro immuno-assay (58). The mechanism for BK release by a lysinespecific proteinase is somewhat puzzling and it is more likely that, as indicated in their results, the enzyme preparation was significantly contaminated by activity cleaving after arginine residues (probably by RGP-1). Thus, it is likely that the release of $\mathrm{BK}$ in these assays was due to cleavage by both enzymes at the positions shown above in HMWK. An arginine-specific proteinase isolated by Hinode et al. (59) did not generate BK directly from HMWK in vitro, consistent with our results; however, another proteinase has been claimed to cleave after both arginine and lysine bonds, generating BK from HMWK directly (60). Thus, although it may be possible to directly release BK from HMWK, much higher concentrations of the enzymes are required which, together with inhibitor studies, suggests that this would not be a significant mechanism in vivo, in relation to the activation of PK by low concentrations of RGP-1 as elucidated here.

The immunization of animals with whole cells of $P$. ging $i$ valis, or its components, has been shown to be protective against experimental infection with the bacteria (61-63). Since the existence of $P$. gingivalis and other periopathogens in the dentogingival crevice depends heavily on the continuous supply of nutrients delivered to periodontitis sites by GCF, it can be speculated that inhibition of GCF production may affect bacterial growth and/or virulence. Because RGP-1 is the major VPE factor of $P$. gingivalis and the VPE activity was blocked by RGP-1-specific antibody (Fig. 7), it can be envisaged that immunization with purified RGP-1 may protect against $P$. gingivalis infection, a hypothesis which is now under investigation in our laboratory using a mouse model.

\section{Acknowledgments}

This work was supported in part by National Institutes of Health grant.

\section{References}

1. Shaw, J. H. 1987. Causes and control of dental caries. N. Eng. J. Med. 317:996-1004.

2. Williams, R. C. 1990. Periodontal disease. N. Eng. J. Med. 322:373-382.

3. Slots, J. 1977. The predominant cultivable microflora of advanced periodontitis. Scand. J. Dent. Res. 85:114-121.

4. Tanner, A. C., C. Haffer, G. T. Bratthall, R. A. Visconti, and S. S. Socransky. 1979. A study of the bacteria associated with advancing periodontitis in man J. Clin. Periodont. 6:278-307.

5. Spiegel, C. A., S. E. Hayduk, G. E. Minah, and G. N. Krywolap. 1979. Black-pigmented Bacteroides from clinically characterized periodontal sites. J. Periodont. Res. 14:376-382.

6. White, D., and D. Mayrand. 1981. Association of oral Bacteroides with gingivitis and adult periodontitis. J. Periodont. Res. 16:259-265.

7. Zambon, J. J., H. S. Reynold, and J. Slots. 1981. Black-pigmented Bacteroides Spp. in the human oral cavity. Infect. Immunol. 32:198-203.

8. Holt, S. C., J. Ebersole, J. Felton, M. Brunsvold, and K. S. Kornmann. 1987. Implantation of Bacteroides gingivalis in nonhuman primates initiates progression of Periodontitis. Science (Wash. DC). 239:55-57.

9. Smalley, J. W., A. J. Birss, H. M. Kay, A. S. McKee, and P. D. Marsh. 1989. The distribution of trypsin-like enzyme activity in cultures of a virulent and an avirulent strain of Bacteroides gingivalis W50. Oral Microbiol. Immunol. 4:178-179.

10. Marsh, P. D., A. S. McKee, A. S. McDermid, and A. B. Dowsett. 1989 Ultrastructure and enzyme activities of a virulent and an a virulent varient of Bacteroides gingivalis W50. FEMS Microbiol. Lett. 59:181-186.

11. Grenier, D., and D. Mayrand. 1987. Selected characteristics of pathogenic and nonpathogenic strains of Bacteroides gingivalis. J. Clin. Microbiol. 25:738740 .

12. Sundqvist, G., J. Carlsson, B. Herrmann, and A. Tärnvik. 1985. Degradation of human immunoglobulins $\mathrm{G}$ and $\mathrm{M}$ and complement factors $\mathrm{C} 3$ and $\mathrm{C} 5$ by black-pigmented Bacteroides. J. Med. Microbiol. 19:85-94.

13. Schenkein, H. A., and C. R. Berry. 1988. Production of chemotactic factors for neutrophils following the interaction of Bacteroides gingivalis with purified C5. J. Periodont. Res. 23:308-312.

14. Sundqvist, G., A. Bengton, and J. Carlsson. 1988. Generation and degradation of the complement fragment C5a in human serum by Bacteroides gingivalis. Oral Microbiol. Immunol. 3:103-107.

15. Wingrove, J. A., R. G. DiScipio, Z. Chen, J. Potempa, J. Travis, and T. E. Hugli. 1992. Activation of complement components $\mathrm{C} 3$ and $\mathrm{C} 5$ by a cysteine proteinase (Gingipain-1) from Porphyromonas (Bacteroides) gingivalis. J. Biol. Chem. 267:18902-18907. 
16. Sundqvist, G., J. Carlsson, and L. Hänström. 1987. Collagenolytic activity of black-pigmented Bacteroides species. J. Periodont. Res. 22:300-306.

17. Birkedal-Hansen, H., R. E. Taylor, J. J. Zambon, P. K. Barwa, and M. E. Neiders. 1988. Characterization of collagenolytic activity from strains of Bacteroides gingivalis. J. Periodont. Res. 23:258-264.

18. Brill, N. 1960. Gingival conditions related to flow of tissue fluid into gingival pockets. Acta Odontol. Scand. 18:421-446.

19. Löe, H., and P. Holm-Pedersen. 1965. Absence and presence of fluid from normal and inflamed gingivae. Periodontics. 3:171-177.

20. Oliver, R. C., P. Holm-Pedersen, and H. Löe. 1969. The correlation between clinical scoring, exudate measurements and microscopic evaluation of inflammation of the gingiva. J. Periodont. 40:201-209.

21. Rudin, H. J., H. F. Overdiek, and K-H. Rateischak. 1970. Correlation between fluid rate and clinical and histological inflammation of the marginal gingiva. Helv. Odontol. Acta. 14:21-26.

22. Cimasoni, G. 1983. Crevicular fluid updated. In Monographs in Oral Science. Vol. 12. H. M. Mayers, editor. Krager, Basel, Switzerland. 29-44.

23. Brecx, M. C., K. Schlegel, P. Gehr, and N. P. Lang. 1987. Comparison between histological and clinical parameters during human experimental gingivitis. J. Periodont. Res. 22:50-57.

24. Henskens, Y. M. C., U. van der Velden, E. C. I. Veerman, and A. V. Nieuw Amerongen. 1992. Protein, albumin and cystatin concentrations in saliva of healthy subjects and of patients with gingivitis or periodontitis. J. Periodont. Res. 28:43-48.

25. Hugli, T. E. 1986. Biochemistry and biology of anaphylatoxins. Complement. 3:111-127.

26. Imamura, T., T. Yamamoto, and T. Kambara. 1984. Guinea pig plasma kallikrein as a vascular permeability enhancement factor: its dependence on kinin generation and regulation mechanisms in vivo. Am. J. Pathol. 115:92-101.

27. Yamamoto, T., K. Kozono, T. Kambara, and C. G. Cochrane. 1988. The Hageman factor-dependent system in the vascular permeability reaction. Biochim. Biophys. Acta. 966:196-206.

28. Matsumoto, K., T. Yamamoto, R. Kamata, and H. Maeda. 1984. Pathogenesis of serratial infection: activation of the hageman factor-prekallikrein cascade by serratial protease. J. Biochem. 96:739-749.

29. Molla, A., T. Yamamoto, T. Akaike, S. Miyoshi, and H. Maeda. 1989. Activation of Hageman factor and prekallikrein and generation of kinin by various microbial proteinases. J. Biol. Chem. 264:10589-10594.

30. Yamamoto, T., Y. Shibuya, N. Nishino, H. Okabe, and T. Kambara. 1990 Activation of human Hageman factor by Psaudomonas aeruginosa elastase in the presence or absence of negatively charged substance in vitro. Biochim. Biophys. Acta. 1038:231-239.

31. Aschner, J. L., J. M. Lennon, J. W. Fenton II, M. Aschner, and A. B. Malik. 1990. Enzymatic activity is necessary for thrombin-mediated increase in endothelial permeability. Am. J. Physiol. 259:270-275.

32. Senior, R. M., W. F. Skodgen, G. L. Griffin, and G. D. Wilner. 1986 Effect of fibrinogen derivatives upon the inflammatory response: studies with human fibrinopeptide B. J. Clin. Invest. 77:1014-1019.

33. Nilsson, T., J. Carlsson, and G. Sundqvist. 1985. Inactivation of key factors of the plasma proteinase cascade system by Bacteroides gingivalis. Infect. Immun. 50:467-471.

34. Chen, Z., J. Potempa, A. Polanowski, M. Wikström, and J. Travis. 1992. Purification and characterization of a 50-kDa cysteine proteinase (Gingipain) from Porphyromonas gingivalis. J. Biol. Chem. 267:18896-18901.

35. Pike, R., W. McGraw, J. Potempa, and J. Travis. Lysine- and argininespecific proteinases from Porphyromonas gingivalis: isolation, characterization, and evidence for the existence of complexes with hemagglutinins. J. Biol. Chem. 269:406-411.

36. Udaka, K., Y. Takeuchi, and H. Z. Movat. 1970. Simple method for quantitation of enhanced vascular permeability. Proc. Soc. Exp. Biol. Med. 133:1384-1387.

37. Polson, A., G. M. Potgieter, J. F. Largier, E. G. F. Mears, and F. J. Joubert. 1964. The fractionation of protein mixtures by linear polymers of high molecular weight. Biochim. Biophys. Acta. 82:463-475.

38. Engel, S. L., T. R. Schaeffer, B. I. Gold, and B. Rubin. 1972. Inhibition of pressor effects of angiotensin I and augmentation of depressor effects of bradykinin by synthetic peptides. Proc. Soc. Exp. Biol. Med. 140:240-244.

39. Wuepper, K. D., and C. G. Cochrane. 1972. Plasma prekallikrein: Isolation, characterization, and mechanism of activation. J. Exp. Med. 135:1-20.

40. Yang, H. Y. T., and E. G. Erdös. 1967. Second kininase in human blood plasma. Nature (Lond.). 215:1402-1403.

41. Bouma, B. N., D. M. Kerbiriou, R. A. A. Vlooswijk, and J. H. Griffin
1980. Immunological studies of prekallikrein, kallikrein and high molecularweight kininogen in normal and deficient plasmas and in normal plasma after cold-dependent activation. J. Lab. Clin. Med. 96:693-709.

42. Chung, D. W., K. Fujikawa, B. A. MacMullen, and E. W. Davie. 1986 Human plasma prekallikrein, a zymogen to a serine protease that contains four tandem repeats. Biochemistry. 25:2410-2417.

43. Cochrane, C. G., S. D. Revak, and K. D. Wuepper. 1973. Activation of Hageman factor in solid and fluid phases. A critical role of kallikrein. J. Exp. Med. 138:1564-1583.

44. Revak, S. D., C. G. Cochrane, A. R. Johnston, and T. E. Hugli. Structural changes accompanying enzymatic activation of human Hageman factor. J. Clin. Invest. 54:619-627.

45. Cochrane, C. G., and S. D. Revak. Dissemination of contact activation in plasma by plasma kallikrein. J. Clin. Invest. 152:608-619.

46. Dunn, J. T., M. Silverberg, and A. P. Kaplan. 1982. The cleavage and formation of activated Hageman factor by autodigestion and by kallikrein. J. Biol. Chem. 257:1779-1784.

47. Mandle, R. Jr., and A. P. Kaplan. 1977. Hageman factor substrates. Human plasma prekallikrein: Mechanism of activation by Hageman factor and participation in Hageman factor-dependent fibrinolysis. J. Biol. Chem. 252:6097-6104.

48. Bouma, B. N., L. A. Miles, G. Beretta, and J. H. Griffin. 1980. Human plasma prekallikrein. Studies of its activation by activated factor XII and of its inactivation by diisopropyl phosphofluoridate. Biochemistry. 19:1151-1160.

49. Shibuya, Y., H. Tanaka, N. Nishino, H. Okabe, T. Kambara, and T. Yamamoto. 1991. Activation of human plasma prekallikrein by Pseudomonas aeruginosa elastase in vitro. Biochim. Biophys. Acta. 1097:23-27.

50. Tanaka, H., T. Yamamoto, Y. Shibuya, N. Nishino, S. Tanase, Y. Miyauchi, and T. Kambara. 1992. Activation of human plasma prekallikrein by Pseudomonas aeruginosa elastase. II. Kinetic analysis and identification of scissile bond of prekallikrein in the activation. Biochim. Biophys. Acta. 1138:243-250.

51. Maruo, K., T. Akaike, Y. Matsumura, S. Kohmoto, Y. Inada, T. Ono, T. Arao, and H. Maeda. 1991. Triggering of the vascular permeability reaction by activation of the Hageman factor-prekallikrein system by house dust mite proteinase. Biochim. Biophys. Acta. 1074:62-68.

52. Takahashi, K., T. Aoki, S. Kohmoto, H. Nishimura, Y. Kodera, A. Matsushima, and Y. Inada. 1990. Activation of kallikrein-kinin system in human plasma with purified serine protease from Dermatophagoides farinae. Int. Arch. Allergy Appl. Immunol. 91:80-85.

53. Maruo, K., T. Akaike, Y. Inada, I. Ohkubo, T. Ono, and H. Maeda 1993. Effect of microbial and mite proteases on low and high molecular weight kininogens. J. Biol. Chem. 268:17711-17715.

54. Smalley, J. W., and A. J. Birss. 1987. Trypsin-like enzyme activity of the extracellular membrane vesicles of Bacteroides gingivalis W50. J. Gen. Microbiol. 133:2883-2894.

55. Minhas, T., and J. Greenman. 1989. Production of cell-bound and vesicleassociated trypsin-like protease, alkaline phosphatase and $\mathrm{N}$-acetyl- $\beta$-glucosaminidase by Porphyromonas gingivalis W50. J. Gen. Microbiol. 135:557-564.

56. Williams, D. M., F. J. Hughes, E. W. Odell, and P. M. Farthing. 1992. Pathology of Periodontal Disease. Oxford University Press, Oxford. 90 pp.

57. Kellerman, J., F. Lottspeich, A. Henschen, and W. Müller-Esterl. 1986. Completion of the primary structure of human high-molecular-mass kininogen. Eur. J. Biochem. 154:471-478.

58. Scott, C. F., E. J. Whitaker, B. F. Hammond, and R. W. Colman. 1992. Purification and characterization of a potent $70-\mathrm{kDa}$ thiol lysyl-proteinase (Lysgingivain) from Porphyromonas gingivalis that cleaves kininogens and fibrinogen J. Biol. Chem. 268:7935-7942.

59. Hinode, D., H. Hayashi, and R. Nakamura. 1991. Purification and characterization of three types of proteases from culture supernatants of Porphyromonas gingivalis. Infect. Immunol. 59:3060-3068.

60. Hinode, D., A. Nagata, S. Ichiyama, H. Hayashi, M. Morioka, and R. Nakamura. 1992. Generation of plasma kinin by three types of protease isolated from Porphyromonas gingivalis 381. Archs. Oral. Biol. 37:859-861.

61. Chen, P. B., L. B. Davern, R. Schifferle, and J. J. Zambon. 1990. Protective immunization against experimental Bacteroides (Porphyromonas) gingivalis in fection. Infect. Immunol. 58:3394-3400.

62. Kesavalu, L., L. Ebersole, R. L. Machen, and S. C. Holt. 1992. Porphyromonas gingivalis virulence in mice: induction of immunity to bacterial components. Infect. Immunol. 60:1455-1464.

63. Evans, R. T., B. Klausen, H. T. Sojar, G. S. Bedi, C. Sfintescu, N. S. Ramamurthy, L. M. Golub, and R. J. Genco. 1992. Immunization with Porphyromonas (Bacteroides) gingivalis fimbriae protects against periodontal destruction. Infect. Immunol. 60:2926-2935. 